\title{
Traditional $v$. modified dietary patterns and their influence on adolescents' nutritional profile
}

\author{
YoonJu Song ${ }^{1}$, Hyojee Joung ${ }^{2}$, Katrin Engelhardt ${ }^{2}$, Sun Young Yoo ${ }^{3}$ and Hee Young Paik ${ }^{3}$ \\ ${ }^{1}$ Human Ecology Research Center, Department of Food and Nutrition, Seoul National University, Seoul, Korea \\ ${ }^{2}$ Graduate School of Public Health \& Research Institute of Health and Environment, Seoul National University, 28 Yungun-dong, \\ Chongro-gu, Seoul 110-799, Korea \\ ${ }^{3}$ Department of Food and Nutrition, Seoul National University, Seoul, Korea
}

(Received 23 August 2004 - Revised 24 December 2004 - Accepted 20 January 2005)

Korea has experienced exceptionally rapid economic developments. Even though the country has managed to maintain aspects of its traditional diet, dietary habits are changing, especially among adolescents. This study was carried out to identify prevailing dietary patterns among Korean adolescents and to compare the nutrient intakes and dietary behaviours between the patterns. A 3 d diet record, collected from 671 Korean adolescents aged $12-14$ years in Seoul, Korea, was assessed. By cluster analysis, subjects were classified into a modified $(69.9 \%)$ and a traditional (30.1\%) dietary pattern group. The modified group consumed more bread, noodles, cookies and pizza/hamburgers compared with the traditional group, which consumed mainly rice and kimchi (fermented cabbage). The modified group had significantly higher intakes of all nutrients. It had a higher total daily energy intake (7719 kJ), a higher daily energy intake from fat $(29.8 \%)$ and a higher cholesterol intake $(326 \mathrm{mg} / \mathrm{d})$, compared with the traditional group (6686 kJ, $24.8 \%$ and $244 \mathrm{mg} / \mathrm{d}$, respectively). The modified group was more likely to consume fast foods, fried foods and carbonated beverages even though they consumed more fresh fruits and milk, while the traditional group was more likely to have a rice-based diet and not to skip breakfast. These results suggest that monitoring dietary behaviours of adolescents, especially in a society experiencing a nutrition transition, is necessary in order to identify both negative and positive changes in respect of risk factors for nutrition-related chronic diseases as well as for undernutrition.

Korea: Adolescents: Dietary patterns: Cluster analysis

There is increased interest in examining the relationship between dietary patterns and other factors such as chronic disease, overall nutrient quality and demographic variables, since dietary patterns summarize complex dietary data into more practical, meaningful information. Dietary pattern analyses contribute to a better understanding of the relationship between diet and disease, which is important for public health practice such as developing targeted dietary interventions and educational programmes (Akin et al. 1986; Wirfalt \& Jeffery, 1997; Schulze et al. 2001; Wirfalt et al. 2001; Hu, 2002; Millen et al. 2002; Berrigan et al. 2003).

Previous studies with adults have shown significant relationships between dietary patterns and disease risks, despite the different methods used (e.g. cluster or factor analysis) and the different variables selected for defining the dietary patterns. Dietary patterns were found to be related to the risk of CHD among US men (Hu et al. 2000); to the risk of CVD among US women (Millen et al. 2002); and to the metabolic syndrome, including insulin resistance and hypertension, among Swedish men and women (Wirfalt et al. 2001). Demographic or socioeconomic characteristics, e.g. age, gender, education, income and ethnicity, were also found to differ between dietary patterns among adults (Aranceta et al. 2003; Berrigan et al. 2003; Hulshof et al. 2003; Martikainen et al. 2003; Sanchez-Villegas et al. 2003). In addition, nutrient intakes or eating behaviours were found to differ across dietary patterns (Akin et al. 1986; Wirfalt \& Jeffery, 1997; Schulze et al. 2001).

The relationship between dietary patterns and disease risk has been shown among adults, but only a few studies investigated this relationship among adolescents. It has long been recognized that it is important to establish healthy eating behaviours in the early stages of life and to have a favourable nutrient profile (Jackson et al. 2002; Story et al. 2002; Matthys et al. 2003; Videon \& Manning, 2003). Several studies indicated that Korean adolescents' dietary behaviours are changing from a traditional, rice and plant-based diet, to a Western, high fat and animal food diet (Kim et al. 2000; Lee et al. 2002; Park et al. 2003). Korean adolescents had poor eating behaviours, including, for example, skipping meals, snacking, eating out frequently and dieting, especially among girls (Choi et al. 1997; Kim et al. 1998; Hong, 1999). The overall nutritional status of adolescents does not appear to be as good as that of other age groups in Korea (Shim et al. 2001; Ministry of Health and Welfare, 2001).

To our knowledge there are no studies that investigate Korean adolescents' dietary patterns, the extent to which Korean adolescents have adopted a Western diet, and how a dietary pattern change might influence the adolescents' nutritional situation. The purpose of the present study was to identify prevailing dietary patterns based on the foods typically consumed by Korean 
adolescents, to compare the nutrient intakes and dietary behaviours between the identified patterns and to investigate whether and to what extent the groups meet the Korean RDA and follow the Korean Dietary Guidelines.

\section{Subjects and methods}

\section{Study population and data collection}

Data were obtained from one public school in Seoul, South Korea. The initial study population included all 721 students attending seventh and eighth grade, aged 12-14 years, of a school located in the north-western part of Seoul that does not have a school lunch cafeteria. During the first visit to the school, questionnaires for general characteristics and dietary behaviours were distributed. Trained project staff provided the participants with detailed instructions about how to keep $3 \mathrm{~d}$ diet records. At the second visit, anthropometric measurements including height, weight and body composition were collected. The completed $3 \mathrm{~d}$ diet records were reviewed by trained dietitians and incomplete or unclear records were discussed with the students. Of the 721 students, 671 individuals $(93.1 \%)$ with completed $3 \mathrm{~d}$ diet records were included in the analysis. The study protocol was reviewed and approved by the Institutional Review Board of the Graduate School of Public Health, Seoul National University.

\section{Study measures}

The first part of the self-administered questionnaire used in this study included demographic variables such as age, gender, educational level of parents and household economic status. The adolescents were asked to indicate both their mother's and father's highest level of attained education. Educational level was categorized into three groups (middle school or less, high school, and college or more). Adolescents were also asked to judge their household economic status by selecting one of three categories: high; middle; low. The second part of the questionnaire assessed students' dietary behaviours including their food preferences and their eating habits. Body composition was measured by bioelectrical impedance analysis using Inbody 2.0 (Biospace Co. Ltd, Seoul, Korea).

Three-day records, including two weekdays and $1 \mathrm{~d}$ on the weekend, were used to collect dietary intake data. Food models, pictures and detailed instructions were provided to maximize the accuracy of recording all foods and portion sizes at the first visit. The teachers motivated and reminded their students to keep their food records between the first and the second visit. Students' daily nutrient intakes were calculated from the recorded food items using the Korean Nutrient Database (Korean Nutrition Society, 2000).

\section{Dietary patterns}

The dietary intake information collected with $3 \mathrm{~d}$ records was categorized into twenty-one groups, according to food groups identified in the Korean Nutrient Database (Korean Nutrition Society, 2000). For the purpose of the present study, some categories were modified to be able to address the food items typically consumed by adolescents, such as pizza, hamburgers, cookies, chips, etc. Therefore, the grain and grain product group was divided into seven subgroups: white rice; other grains; noodles and ramen (a Korean instant noodle soup); flour and bread; breakfast cereals; cookies and chips; pizza and hamburger. Kimchi (a traditional fermented cabbage) was separated into a single vegetable group because kimchi is one of the main Korean side dishes. Legumes and nuts, and fish and seaweeds were combined. The food groups and food items used in this study are shown in Table 1.

Cluster analysis was used to group the subjects according to dietary patterns. In the present study, we defined the dietary patterns using the percentage of total energy from food groups.

\section{Nutritional profiles}

Nutritional profiles including nutrient intakes and dietary behaviours were compared between the two identified dietary patterns. Nutrient intakes were calculated from $3 \mathrm{~d}$ diet records as absolute intake and as a percentage of Korean RDA (Korean Nutrition Society, 2000). Dietary behaviours were assessed in two ways. One assessed how well subjects followed the seven Korean Dietary Guidelines for adolescents (Korean Health Industry Development Institute, 2003). One of the guidelines ('Learning to choose safe foods') was excluded, because no measurement was available. The accomplishment of the other six guidelines was assessed by comparing them to the total frequencies of foods consumed, as identified from the $3 \mathrm{~d}$ records. If the reported serving size of a food item was more than $30 \mathrm{~g}$ for solid foods (e.g. onethird of a bowl of rice) and $100 \mathrm{ml}$ (half a cup) for fluids, the item was counted as one frequency (consumption). Vegetables were counted as total frequencies without considering serving size because vegetables are always used as ingredients of side dishes in Korean meals. The other way that dietary behaviour was

Table 1. Food groupings used in the dietary pattern analysis

\begin{tabular}{ll}
\hline Food group & Food items \\
\hline White rice & White rice \\
Other grain & Brown rice, barley, millet, maize, etc. \\
Noodles and ramen & Noodle, ramen, so myon, udong, etc. \\
Flour and bread & Wheat flour, breads, doughnuts, cakes, etc. \\
Cereals & Breakfast cereals \\
Cookie, cracker and chip & Cracker, snack, cookie, popcorn, biscuits, chip \\
Pizza and hamburger & Pizza, hamburger, sandwich \\
Potatoes & Potato, french fried potato, sweet potato \\
Sugars and sweets & White sugar, honey, candy, chocolates, jelly, \\
& caramel \\
Legumes and nuts & Soyabean, soyabean curd, green peas, red \\
& bean, peanuts, almonds, etc. \\
Vegetables & All kinds of vegetables, mushrooms \\
Kimchi & All kinds of kimchi (Korean fermented \\
& cabbage) \\
Fruits & Citrus fruit, strawberry, melon, banana, pear, \\
& peach, orange, kiwi, fruit juices \\
Meats & Beef, pork \\
Meat products & Ham, sausage, meatball, bacon \\
Poultry & Chicken, turkey \\
Eggs & Egg, cooked egg, fried egg \\
Fishes and seaweeds & Mackerel, bastard halibut, flat fish, canned \\
Milk and dairy products & tuna, anchovy, squid, etc. \\
Milk, flavoured milk, ice cream, yoghurt, \\
cheese
\end{tabular}


assessed was to evaluate the results from the dietary questionnaire such as eating out, consuming a balanced diet and the type of breakfast consumed.

\section{Statistical analysis}

Data were analysed using the Statistical Analysis System (SAS version 8.1, SAS Institute, Cary, NC, USA). Food pattern groups were divided using cluster analysis (PROC FASTCLUS) based on Ward's minimum variance. Consumption of food groups, demographic variables, nutrient intakes and other dietary behaviours were compared between the patterns using the Student's $t$ test or the generalized linear model adjusted for gender. Variables for multiple comparisons of categories were compared between the patterns using the $\chi^{2}$ test.

\section{Results}

The first two clusters seemed most appropriate to capture the dietary pattern in this sample. One cluster included $69.9 \%$, and the other $30.1 \%$ of the total subjects. The consumption of food groups differed by clusters, as shown in Table 2 . White rice, kimchi and fish were consumed significantly higher in the smaller group than in the larger group; while noodles, bread, cookie, pizza and sweets were consumed significantly higher in the larger group. Milk, fruits and beverage were also consumed more in the larger group. Accordingly, the smaller group was labelled the 'traditional group', and the other was labelled the 'modified group'.

Table 3 presents demographic and anthropometric characteristics of the two groups. The groups were comparable in age, but not in gender. Mothers of the subjects in the modified group tended to

Table 2. Mean daily percentage energy from each food group by dietary pattern groups using cluster analysis

\begin{tabular}{|c|c|c|c|c|c|}
\hline \multirow[b]{3}{*}{ Food group } & \multicolumn{4}{|c|}{ Energy from each food group (\%) } & \multirow[b]{3}{*}{$P^{\star}$} \\
\hline & \multicolumn{2}{|c|}{$\begin{array}{c}\text { Modified } \\
\text { group }(n 469)\end{array}$} & \multicolumn{2}{|c|}{$\begin{array}{c}\text { Traditional } \\
\text { group }(n \text { 202) }\end{array}$} & \\
\hline & Mean & SD & Mean & SD & \\
\hline White rice & $25 \cdot 1$ & $7 \cdot 1$ & 44.5 & $8 \cdot 3$ & 0.0001 \\
\hline Other grain & 3.4 & $4 \cdot 3$ & $2 \cdot 4$ & 3.7 & 0.0016 \\
\hline Noodles and ramen & $11 \cdot 3$ & $9 \cdot 3$ & 4.4 & $6 \cdot 3$ & 0.0001 \\
\hline Flour and bread & $5 \cdot 8$ & $6 \cdot 0$ & $3 \cdot 3$ & 4.6 & 0.0001 \\
\hline Cereals & 0.7 & $2 \cdot 3$ & 0.3 & 1.4 & NS \\
\hline Cookie, cracker and chip & 4.4 & 5.9 & $2 \cdot 3$ & 3.8 & 0.0001 \\
\hline Pizza and hamburger & $2 \cdot 6$ & $5 \cdot 2$ & $1 \cdot 7$ & 4.6 & 0.0384 \\
\hline Potatoes & 1.4 & 2.5 & 1.0 & $1 \cdot 7$ & 0.004 \\
\hline Sugars and sweets & 1.9 & $2 \cdot 2$ & $1 \cdot 3$ & 1.4 & 0.0001 \\
\hline Legumes and nuts & 1.9 & $2 \cdot 4$ & $2 \cdot 2$ & $2 \cdot 8$ & NS \\
\hline Vegetables & 0.5 & 0.4 & 0.7 & 0.5 & 0.0134 \\
\hline Kimchi† & 1.5 & $1 \cdot 0$ & $1 \cdot 7$ & $1 \cdot 1$ & 0.0001 \\
\hline Fruits & $2 \cdot 7$ & 3.4 & 1.6 & 2.9 & 0.0001 \\
\hline Meats & $3 \cdot 2$ & $5 \cdot 3$ & $2 \cdot 7$ & $4 \cdot 7$ & NS \\
\hline Meat products & $7 \cdot 6$ & $6 \cdot 6$ & $6 \cdot 7$ & 5.7 & 0.0001 \\
\hline Poultry & 3.9 & 4.4 & $4 \cdot 2$ & $4 \cdot 2$ & NS \\
\hline Eggs & 2.4 & $2 \cdot 2$ & $2 \cdot 4$ & 2.5 & NS \\
\hline Fishes and seaweeds & 3.4 & $3 \cdot 1$ & $3 \cdot 8$ & $3 \cdot 1$ & 0.0516 \\
\hline Milk and dairy products & $8 \cdot 2$ & $6 \cdot 7$ & $5 \cdot 2$ & $4 \cdot 8$ & 0.0001 \\
\hline Seasonings & 6.5 & $3 \cdot 1$ & $6 \cdot 7$ & 3.5 & NS \\
\hline Beverages & $1 \cdot 7$ & $2 \cdot 5$ & 0.9 & 1.6 & 0.0004 \\
\hline
\end{tabular}

${ }^{*} P$ value from generalized linear model adjusted for gender.

† Korean fermented cabbage.
Table 3. Demographic and anthropometric characteristics by dietary pattern groups

\begin{tabular}{|c|c|c|c|c|c|}
\hline & \multicolumn{2}{|c|}{$\begin{array}{c}\text { Modified } \\
\text { group (n 469) }\end{array}$} & \multicolumn{2}{|c|}{$\begin{array}{c}\text { Traditional } \\
\text { group (n 202) }\end{array}$} & \multirow[b]{2}{*}{$P$} \\
\hline & Mean & SD & Mean & SD & \\
\hline Age (years) ${ }^{*}$ & $13 \cdot 0$ & 0.8 & $12 \cdot 8$ & 0.8 & NS \\
\hline Gender - \% male† & $47 \cdot 8$ & & 61.9 & & 0.001 \\
\hline Mother's education (\%)† & & & & & NS \\
\hline$<$ Middle & 4.0 & & 4.8 & & \\
\hline High school & $48 \cdot 6$ & & $54 \cdot 8$ & & \\
\hline$>$ College & $47 \cdot 4$ & & $40 \cdot 3$ & & \\
\hline \multicolumn{3}{|c|}{ Household economic status (\%)† } & & & NS \\
\hline High & $11 \cdot 6$ & & $16 \cdot 9$ & & \\
\hline Middle & $87 \cdot 8$ & & $82 \cdot 1$ & & \\
\hline Low & 0.6 & & 1.0 & & \\
\hline \multicolumn{6}{|l|}{ BMI $\left(\mathrm{kg} / \mathrm{m}^{2}\right) \ddagger$} \\
\hline Male & $20 \cdot 7$ & $3 \cdot 2$ & $21 \cdot 1$ & 3.5 & NS \\
\hline Female & $20 \cdot 1$ & 3.0 & $19 \cdot 7$ & 3.0 & NS \\
\hline \multicolumn{6}{|l|}{ Body fat $(\%) \ddagger$} \\
\hline Male & $21 \cdot 2$ & $6 \cdot 9$ & $22 \cdot 5$ & $7 \cdot 1$ & NS \\
\hline Female & $27 \cdot 0$ & $5 \cdot 7$ & $26 \cdot 5$ & $6 \cdot 0$ & NS \\
\hline
\end{tabular}

have a higher educational level than those in the traditional group, but the difference was not significant. Household economic status was also comparable between the groups.

There were no significant differences in BMI or in the percentage body fat between the groups in gender-specific comparisons.

The results of the comparison between the two groups' average daily nutrient intakes collected with the $3 \mathrm{~d}$ diet records are shown in Table 4. The average energy intake of the traditional group was $6686 \mathrm{KJ}$, which was significantly lower than that of the modified group $(7719 \mathrm{~kJ})(P<0 \cdot 001)$.

The intake of all nutrients in the modified group was significantly higher than that in the traditional group. The mean percentage of energy intake from carbohydrates was 60 in the traditional group, which was significantly higher than in the modified group (55) $(P<0 \cdot 001)$. In contrast, the mean percentage of energy intake from fat was almost 30 in the modified group, which was significantly higher than in the traditional group (24.8). The mean cholesterol intake in the modified group was $326 \mathrm{mg}$, and that of the traditional group was $244 \mathrm{mg}$. After adjusting for gender and energy, all nutrients except $\mathrm{Fe}$ and vitamin $\mathrm{C}$ remained significantly different between the two groups, and were higher in the modified group.

The nutrient intake was also compared between two groups as a percentage of the Korean RDA (Korean Nutrition Society, 2000) as shown in Table 5. Students from both groups only met the RDA for protein, $\mathrm{P}$, thiamine and niacin. The traditional group's Ca intake was only $39 \%$ of the RDA and the modified group consumed about half of the recommended amount. Almost all subjects (97\%) consumed less than $75 \%$ of the RDA for $\mathrm{Ca}$ in the traditional group compared with $86 \%$ in the modified group (data not shown). The consumption of $\mathrm{Fe}$ was lower in the traditional group than in the modified group (62\% and $84 \%$ of RDA, respectively).

Whether or not the subjects met the Korean Dietary Guidelines for adolescents was evaluated as shown in Table 6. Fast foods, fried foods and carbonated beverages were consumed more in the modified group than in the traditional group. However, fresh 
Table 4. Mean daily nutrient intake from $3 d$ records by dietary pattern groups

\begin{tabular}{|c|c|c|c|c|c|c|}
\hline \multirow[b]{2}{*}{ Nutrients } & \multicolumn{2}{|c|}{ Modified group ( $n$ 469) } & \multicolumn{2}{|c|}{ Traditional group (n 202) } & \multicolumn{2}{|c|}{$P^{*}$} \\
\hline & Mean & SD & Mean & SD & Adjusted for gender & Adjusted for gender, energy \\
\hline Protein (g) & 70 & 23 & 57 & 17 & 0.0001 & 0.0001 \\
\hline Fat $(g)$ & 62 & 22 & 42 & 15 & 0.0001 & 0.0001 \\
\hline Carbohydrate (g) & 255 & 70 & 223 & 48 & 0.0001 & 0.0149 \\
\hline $\mathrm{Ca}(\mathrm{mg})$ & 421 & 206 & 325 & 155 & 0.0001 & 0.0007 \\
\hline$P(\mathrm{mg})$ & 955 & 299 & 788 & 224 & 0.0001 & 0.0001 \\
\hline $\mathrm{Fe}(\mathrm{mg})$ & 13 & 22 & 9 & 15 & 0.0302 & NS \\
\hline Vitamin $A(\mu g R E)$ & 517 & 321 & 403 & 253 & 0.0001 & 0.0088 \\
\hline Thiamin $(\mathrm{mg})$ & $1 \cdot 2$ & 0.5 & 0.9 & 0.3 & 0.0001 & 0.0001 \\
\hline Riboflavin (mg) & $1 \cdot 1$ & 0.4 & 0.8 & 0.3 & 0.0001 & 0.0001 \\
\hline Niacin (mg) & 16 & 7 & 13 & 5 & 0.0001 & 0.0001 \\
\hline Vitamin C (mg) & 53 & 34 & 43 & 34 & 0.0016 & NS \\
\hline Zn (mg) & $8 \cdot 2$ & $2 \cdot 9$ & 6.9 & $2 \cdot 3$ & 0.0001 & 0.0001 \\
\hline Folate $(\mu \mathrm{g})$ & 173 & 74 & 137 & 61 & 0.0001 & 0.0006 \\
\hline \multicolumn{7}{|l|}{ \% Energy } \\
\hline Carbohydrate (\%) & 55 & 7 & 60 & 7 & 0.0001 & \\
\hline Protein (\%) & 15 & 3 & 15 & 2 & 0.0641 & \\
\hline Fat $(\%)$ & 30 & 6 & 25 & 6 & 0.0001 & \\
\hline
\end{tabular}

$\mathrm{RE}$, retinol equivalent.

* $P$ value from generalized linear model.

fruits and milk were also consumed more in the modified group. Having a rice-based diet and less skipping breakfast were more popular in the traditional group.

Results of the dietary questionnaire showed that the modified group ate out more often and preferred a Western-style breakfast (cereals and milk), whereas the traditional group preferred a Korean-style breakfast with rice and side dishes $(P<0.01)$ (see Table 7). 'Having a balanced diet at each meal', i.e. eating foods from different food groups at each meal, was comparable between the two groups. Taking dietary supplements, the frequency of skipping meals and snacking were also comparable between groups (data not shown).

\section{Discussion}

The remarkable economic growth of Korea has resulted in changes in lifestyle, dietary behaviours and disease patterns
(Kim et al. 2000). Studies show that the nutrition transition in Korea is under way - especially among adolescents (Kim et al. 1998; Hong, 1999; Shim et al. 2001). Despite the fact that a Westernized diet has been adopted rapidly in Korea by some population groups, many aspects of the traditional diet have also been retained (Kim et al. 2000; Lee et al. 2002). The rapid adoption of Westernized dietary patterns has occurred especially among the younger generation. The present study results support this observation, as two-thirds of the adolescents consumed a more Westernized diet.

The Western-style diet of adolescents in the present study showed negative as well as positive changes. A positive change was that the modified group had significantly higher intakes of most nutrients, including $\mathrm{Ca}$ and $\mathrm{Fe}$. Similar findings were made among a different group of Korean children with Western-style diets, as they also had a higher intake of $\mathrm{Ca}$ and $\mathrm{Fe}$, probably because of a higher consumption of animal foods and milk

Table 5. Nutrient intake as percentage of Korean RDA by dietary pattern group

\begin{tabular}{|c|c|c|c|c|c|}
\hline & \multicolumn{2}{|c|}{ Mean nutrient intake as percentage of Korean RDA } & \multirow[b]{2}{*}{$P^{\star}$} & \multicolumn{2}{|c|}{ Korean RDA† } \\
\hline & Modified group ( $n$ 469) & Traditional group ( $n$ 202) & & Boys & Girls \\
\hline Energy & $83 \cdot 4$ & $71 \cdot 2$ & 0.0001 & 2500 & 2100 \\
\hline Protein & $111 \cdot 3$ & $91 \cdot 6$ & 0.0001 & 70 & 65 \\
\hline $\mathrm{Ca}$ & $50 \cdot 5$ & 38.9 & 0.0001 & 900 & 800 \\
\hline $\mathrm{P}$ & 114.5 & $94 \cdot 2$ & 0.0001 & 900 & 800 \\
\hline $\mathrm{Fe}$ & $83 \cdot 6$ & $61 \cdot 8$ & 0.0123 & 16 & 16 \\
\hline Vitamin A & $77 \cdot 8$ & $61 \cdot 7$ & 0.0001 & 700 & 700 \\
\hline Thiamin & $109 \cdot 0$ & $78 \cdot 6$ & 0.0001 & 1.3 & $1 \cdot 1$ \\
\hline Riboflavin & 78.5 & $57 \cdot 3$ & 0.0001 & 1.5 & 1.3 \\
\hline Niacin & $105 \cdot 4$ & $88 \cdot 2$ & 0.0001 & 17 & 14 \\
\hline Vitamin C & $75 \cdot 6$ & $60 \cdot 8$ & 0.0016 & 70 & 70 \\
\hline $\mathrm{Zn}$ & $75 \cdot 4$ & $62 \cdot 0$ & 0.0001 & 12 & 10 \\
\hline Folate & 74.4 & $60 \cdot 4$ & 0.0001 & 250 & 250 \\
\hline
\end{tabular}

* $P$ value from generalized linear model adjusted for gender.

† Korean Nutrition Society (2000). 
Table 6. Food habits characterized by consumption frequencies of recommended foods in the Korean Dietary Guideline for adolescents

\begin{tabular}{|c|c|c|c|c|c|c|}
\hline & \multicolumn{4}{|c|}{ Sum of frequencies from $3 \mathrm{~d}$ diet records } & \multirow[b]{3}{*}{$P^{*}$} & \multirow[b]{3}{*}{ Reference of serving size† } \\
\hline & \multicolumn{2}{|c|}{$\begin{array}{l}\text { Modified group } \\
\qquad(n 469)\end{array}$} & \multicolumn{2}{|c|}{$\begin{array}{l}\text { Traditional group } \\
\qquad(n \text { 202) }\end{array}$} & & \\
\hline & Mean & SD & Mean & SD & & \\
\hline \multicolumn{7}{|c|}{ Eat plenty of vegetables, fruits, milk and milk products every day } \\
\hline Vegetables & 23.45 & $10 \cdot 92$ & 23.81 & $11 \cdot 32$ & NS & NA \\
\hline Milk & $1 \cdot 39$ & 1.55 & 0.79 & $1 \cdot 13$ & 0.0001 & $\geq 100 \mathrm{ml}$ \\
\hline \multicolumn{7}{|c|}{ Eat only moderate amounts of fried foods or fast foods } \\
\hline Fast foods & 0.36 & 0.64 & 0.24 & 0.60 & 0.0364 & $\geq 30 \mathrm{~g}$ \\
\hline Fried foods & 0.96 & 0.88 & 0.67 & 0.81 & 0.0002 & $\geq 30 \mathrm{~g}$ \\
\hline \multicolumn{7}{|l|}{ Maintain healthy weight for age } \\
\hline$>$ 90th percentile of BMI for age $(\%)$ & $14 \cdot 71$ & & $16 \cdot 83$ & & NS & \\
\hline Boys & $15 \cdot 63$ & & $20 \cdot 80$ & & NS & \\
\hline Girls & 13.88 & & $10 \cdot 39$ & & NS & \\
\hline Carbonated beverage & 0.64 & 0.93 & 0.34 & 0.59 & 0.0002 & $\geq 100 \mathrm{ml}$ \\
\hline \multicolumn{7}{|l|}{ Start your day with breakfast } \\
\hline Breakfast frequency & $2 \cdot 17$ & 0.97 & 2.45 & 0.79 & 0.0001 & $\geq 100 \mathrm{kcal}$ from each breakfast \\
\hline \multicolumn{7}{|l|}{ Enjoy our rice-based diet } \\
\hline White rice & 5.35 & 1.65 & $7 \cdot 02$ & 1.40 & 0.0001 & $\geq 30 \mathrm{~g}$ \\
\hline
\end{tabular}

NA, not applicable.

${ }^{* *} P$ value from generalized linear model after adjusted for gender, except 'Maintain healthy weight for age': $P$ value from $\chi^{2}$ test.

$\dagger$ If the serving size of each food item was more than $30 \mathrm{~g}$ for solid (e.g. one-third of a bowl of rice) and $100 \mathrm{ml}$ for fluid (half a cup), the food was counted as one frequency except for vegetables.

‡ Korean Pediatrics Society (1999).

(Park et al. 2004). However, the modified group also had higher intakes of fat and cholesterol, and a higher consumption of fast foods, fried foods and snack food items, such as cookies and chips, sweets and carbonated beverages. Snacking has been found to contribute to higher levels of daily energy intake and has been shown to be an important source of refined sugars and saturated fatty acids (Bigler-Doughten \& Jenkins, 1987; Jabns et al. 2001; Matthys et al. 2003). In the present study the modified group consumed $30 \%$ of their daily energy intake from fat and about $326 \mathrm{mg}$ cholesterol/d, both values being significantly higher than those consumed by the traditional group. In comparison to other regions such as the USA and Europe (Lambert et al. 2004; Park et al. 2004), the amount of fat consumed by adolescents was comparable with the modified group in the present study. The percentage of energy from fat consumed in Korea has increased from 20.8 in 1998 to 23.4 in 2001 among adolescents aged 13-19 years compared with the national average of about 19, according to the Korean National Health and Nutrition Survey (Ministry of Health and Welfare, 2000, 2001). The rapid nutritional changes in Korean adolescents underline the importance of monitoring the situation carefully.

The present study could have implications on the health status of these adolescents in later life. Despite the identified positive changes, the risk of developing chronic nutrition-related diseases among adolescents in the modified group seemed higher due to the increased intakes of fat and cholesterol, and the higher consumption of animal foods and snack food items. Studies among adults reported that 'Western' dietary patterns increased the risk of some major chronic diseases, irrespective of how the Western dietary patterns are classified. Fung et al. (2001a) found that a Western food pattern was associated with higher plasma biomarkers of obesity and CVD risk in US male health professionals. Similar results were observed in the Nurses Health Study (Fung et al. 2001b). In a large prospective study, Hu et al. (2000) found that the 'Western pattern' had a higher relative risk of CHD incidence than the 'prudent pattern'.

Even though we could not observe a significant difference in BMI or in body fat distribution between the groups, it is pivotal to take the current changes seriously. Mean BMI increased by more than four units between the mid-1960s and 2000 in the USA and prevalence of overweight and obesity has rapidly increased, reaching $20 \%$ in many European countries (Koletzko et al. 2004; Ogden et al. 2004). In the present study, about $15 \%$ of subjects were above the 90th percentile of BMI for age (Korean Pediatrics Society, 1999). For boys, almost $20 \%$ were classified above the 90th percentile of BMI. It implies that the Korean situation has also reached an alarming level.

The following reasons are proposed for why a trend to adopt a more Westernized diet has occurred rapidly for adolescents in Korea. One reason that should be mentioned is 'globalization'. The number of local and foreign fast food restaurants and food companies has increased in Korea and aggressive marketing techniques are commonly used (Sobal, 2001). The younger generation is more likely to experience globalization. Another reason could be convenience. Korean adolescents spend most of the day out of their homes. Westernized foods, including fast foods and snack items, are easy and convenient to buy and are now even becoming cheaper.

Therefore, the nutritional status of Korean adolescents should be monitored not only to identify possible nutrition-related risks for developing chronic disease, but also to promote a healthy diet considering adolescents do not meet the Korean RDA for several nutrients.

The study results should be interpreted in consideration of the following limitations. Even though the present study suggests a 
Table 7. Dietary behaviours by dietary pattern groups

\begin{tabular}{|c|c|c|c|c|c|c|c|}
\hline & \multirow[b]{2}{*}{ Group } & \multicolumn{5}{|c|}{ Frequency (no. of times per week) } & \multirow[b]{2}{*}{$P^{\star}$} \\
\hline & & 7 & $5-6$ & $3-4$ & $1-2$ & 0 & \\
\hline \multirow[t]{2}{*}{ Eating out } & MO & $2 \cdot 1$ & 4.9 & $12 \cdot 0$ & $48 \cdot 1$ & $32 \cdot 8$ & \multirow[t]{2}{*}{0.0268} \\
\hline & TA & $4 \cdot 0$ & 6.0 & $6 \cdot 0$ & $41 \cdot 0$ & 43.0 & \\
\hline \multirow{2}{*}{$\begin{array}{l}\text { Having a } \\
\text { balanced diet } \\
\text { at each meal }\end{array}$} & MO & 43.5 & $15 \cdot 3$ & $18 \cdot 5$ & $13 \cdot 8$ & 8.8 & \multirow[t]{2}{*}{ NS } \\
\hline & TA & $48 \cdot 0$ & $19 \cdot 0$ & $15 \cdot 5$ & $13 \cdot 0$ & 4.5 & \\
\hline \multirow{2}{*}{$\begin{array}{l}\text { Korean-style } \\
\text { breakfast } \\
\text { (rice and side } \\
\text { dishes) }\end{array}$} & MO & $37 \cdot 0$ & $19 \cdot 4$ & $10 \cdot 5$ & $16 \cdot 5$ & $16 \cdot 7$ & \multirow[t]{2}{*}{0.0206} \\
\hline & TA & $48 \cdot 7$ & $20 \cdot 1$ & $10 \cdot 1$ & $10 \cdot 6$ & $10 \cdot 6$ & \\
\hline \multirow{2}{*}{$\begin{array}{l}\text { Western-style } \\
\text { breakfast } \\
\text { (cereal and } \\
\text { milk) }\end{array}$} & MO & $4 \cdot 6$ & $4 \cdot 3$ & $5 \cdot 3$ & $28 \cdot 9$ & $56 \cdot 9$ & \multirow[t]{2}{*}{0.0161} \\
\hline & $\mathrm{TA}$ & 1.7 & 0.6 & 5.7 & 23.4 & 68.6 & \\
\hline
\end{tabular}

${ }^{*} P$ value from $\chi^{2}$ test.

MO, modified group, $n$ 469; TA, traditional group, $n 202$.

trend towards increased adoption of Western-style dietary patterns, our results are not generalizable to all Korean adolescents because our study sample was recruited only from one school in Seoul. Another limitation was that simple questions for some demographic variables, such as educational level and economic status, were used. Asking about income in Korea is culturally inappropriate and adolescents might not be aware of their parents' income. Many studies reported that family incomes, educational level of parents and socio-economic status influenced the dietary pattern of adolescents (Berrigan et al. 2003; Hulshof et al. 2003; Martikainen et al. 2003). Future research is needed to investigate these issues more clearly in Korea.

In conclusion, we found two main dietary patterns for Korean adolescents. The modified group showed similarities with a 'Western dietary pattern', and their diet had both positive as well as negative aspects. While more and more Korean adolescents are starting to consume higher levels of fat and sugar, many Korean adolescents are still deficient in important nutrients. The present results support the necessity to monitor Korean adolescents' dietary behaviours in order to identify negative and positive changes in respect of risk factors for nutrition-related chronic diseases and to enable the development of appropriate and tailored dietary interventions for Korean adolescents.

\section{Acknowledgement}

This work was financially supported by a grant from the Korean Health 21 R\&D Project, Ministry of Health and Welfare, Republic of Korea (03-PJ1-PG3-21 900-0017).

\section{References}

Akin JS, Guilkey DK, Popkin BM \& Fanelli MT (1986) Cluster analysis of food consumption patterns of older Americans. J Am Diet Assoc 86, 616-624.

Aranceta J, Perez-Rodrigo C, Ribas L \& Serra-Majem LI (2003) Sociodemographic and lifestyle determinants of food patterns in Spanish children and adolescents: the enKid study. Eur J Clin Nutr 57, S40-S44.
Berrigan D, Dodd K \& Troiano RP (2003) Patterns of health behaviors in U.S. adults. Prev Med 36, 615-623.

Bigler-Doughten S \& Jenkins RM (1987) Adolescent snacks: nutrient density and nutritional contribution to total intake. J Am Diet Assoc 87, 1678-1679.

Choi JH, Kim JH, Lee MJ, Moon SJ, Lee SI \& Baek NS (1997) An ecological analysis of iron status of middle school students in Seoul. Korean J Nutr 30, 960-975 (in Korean).

Fung TT, Rimm EB, Spiegelman D, Rifai N, Tofler GH, Willett WC \& Hu FB (2001a) Association between dietary patterns and plasma biomarkers of obesity and cardiovascular disease risk. Am J Clin Nutr 73, 61-67.

Fung TT, Willett WC, Stampfer MJ, et al. (2001b) Dietary patterns and risk of coronary heart disease in women. Arch Intern Med 161, $1857-1862$.

Hong YG (1999) A study on the relation of eating behavior and food intake to obesity index of adolescents. Korean J Diet Cult 14, $535-554$ (in Korean).

Hu FB (2002) Dietary pattern analysis: a new direction in nutritional epidemiology. Curr Opin Lididol 13, 3-9.

Hu FB, Rimm EB, Stampfer MJ, Ascherio A, Spiegelman \& Willet WC (2000) Prospective study of major dietary patterns and risk of coronary heart disease in men. Am J Clin Nutr 79, 912-921.

Hulshof KFAM, Brussaard JH, Kruizinga AG, Telman J \& Lowik MRH (2003) Socio-economic status, dietary intake and 10y trends: the Dutch National Food Consumption Survey. Eur J Clin Nutr 57, $128-137$.

Jabns L, Siega-Riz AM \& Popkin BM (2001) The increasing prevalence of snacking among US children from 1977 to 1996. J Pediatr 138, 493-498.

Jackson M, Samms-Vaughan M \& Ashley D (2002) Nutritional status of 11-12-year-old Jamaican children: coexistence of underand overnutrition in early adolescence. Public Health Nutr 5, 281-288.

Kim JH, Choi JH, Lee MJ \& Moon SJ (1998) An ecological study on eating behavior of middle school students in Seoul. Korean J Cотmunity Nutr 3, 292-303, (in Korean).

Kim S, Moon S \& Popkin BM (2000) The nutrition transition in South Korea. Am J Clin Nutr 71, 44-53.

Koletzko B, de la Gueronniere V, Toschke AM \& von Kries R (2004) Nutrition in children and adolescents in Europe: what is the scientific basis? Introduction. Br J Nutr 92, S67-S73.

Korean Health Industry Development Institute (2003) Revision of Dietary Guidelines for Koreans: Dietary Action Guides for Infants \& Toddlers, Pregnant \& Lactating Women, Children, and Adolescents. Seoul: Ministry of Health and Welfare.

Korean Nutrition Society (2000) Recommended Dietary Allowances for Koreans, 7th rev. Seoul: Joonang-Munhwa.

Korean Pediatrics Society (1999) The Growth Chart of Korean Children and Adolescents in 1998. Seoul: Gwang-Moon Publishing Co.

Lambert J, Agostoni C, Elmadfa I, Hulshof K, Krause E, Livingstone B, Socha P, Pannemans D \& Samartin S (2004) Dietary intake and nutritional status of children and adolescents in Europe. Br J Nutr 92, S147-S211.

Lee MJ, Popkin BM \& Kim S (2002) The unique aspects of the nutrition transition in South Korea: the retention of healthful elements in their traditional diet. Public Health Nutr 5, 197-203.

Martikainen P, Brunner E \& Marmot M (2003) Socioeconomic differences in dietary patterns among middle-aged men and women. Soc Sci Med 56, $1397-1410$.

Matthys C, Henauw SD, Devos C \& Backer GD (2003) Estimated energy intake, macronutrient intake and meal pattern of Flemish adolescents. Eur J Clin Nutr 57, 366-375.

Millen BE, Quatromoni PA, Nam BY, O'Horo CE, Polak JF \& D'Agostino RB (2002) Dietary patterns and the odds of carotid atherosclerosis in women: the Framingham nutrition studies. Prev Med 35, 540-547.

Ministry of Health and Welfare (2000) Report on 1998 National Health and Nutrition Survey. Seoul: Ministry of Health and Welfare. 
Ministry of Health and Welfare (2001) Report on 2001 National Health and Nutrition Survey. Seoul: Ministry of Health and Welfare.

Ogden CL, Fryar CD, Carroll MD \& Flegal KM (2004) Mean body weight, height, and body mass index, United States 1960-2002. Adv Data 347, 1-17.

Park MH, Park MS, Paik HY, et al. (2003) Cultural Life in Korea. Seoul: Kyomunsa Ltd.

Park SY, Paik HY, Skinner JD, Spindler AA \& Park HR (2004) Nutrient intake of Korean American, Korean, and American adolescents. $J$ Am Diet Assoc 104, 242-245.

Sanchez-Villegas A, Delgado-Rodriguez M, Martinez-Gonzalez MA \& Irala-Estevez JD (2003) Gender, age, socio-demographic and lifestyle factors associated with major dietary patterns in the Spanish Project SUN. Eur J Clin Nutr 57, 285-292.

Schulze MB, Hoffmann K, Kroke A \& Boeing H (2001) Dietary patterns and their association with food and nutrient intake in the European Prospective Investigation into Cancer and Nutrition (EPIC) - Potsdam study. Br J Nutr 85, 363-373.
Shim JE, Paik HY, Moon HK \& Kim YO (2001) Comparative analysis and evaluation of dietary intake of Koreans by age group: (1) nutrient intakes. Korean J Nutr 34, 554-567 (in Korean).

Sobal J (2001) Commentary: Globalization and the epidemiology of obesity. Int J Epidemiol 30, 1136-1137.

Story M, Neumark-Sztainer D \& French S (2002) Individual and environmental influences on adolescent eating behaviors. J Am Diet Assoc 102, S40-S51.

Videon TM \& Manning CK (2003) Influences on adolescent eating patterns: the importance of family meals. $J$ Adolesc Health 32, 365-373.

Wirfalt AKE \& Jeffery RW (1997) Using cluster analysis to examine dietary patterns: nutrient intakes, gender, and weight status differ across food pattern clusters. $J$ Am Diet Assoc 97, 272-279.

Wirfalt E, Hedblad B, Gullberg B, et al. (2001) Food patterns and components of the metabolic syndrome in men and women: a cross-sectional study within the Malmo diet and cancer cohort. Am J Epidemiol 154, 1150-1159. 